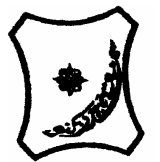

Bayero Journal of Pure and Applied Sciences, 7(2): 8- 12

Received: August 2014

Accepted: November 2014

ISSN $2006-6996$

\title{
ISOLATION OF LISTERIA MONOCYTOGENES RECOVERED FROM SOME READY-TO-EAT FOODS SOLD IN KANO, NORTH-WESTERN NIGERIA
}

\author{
$*^{1}$ Aisha, B.M. and ${ }^{2}$ A.H. Kawo \\ ${ }^{1}$ Department of Bio entrepreneurship and Extension Services, National Biotechnology Development Agency, \\ Abuja, Nigeria ${ }^{2}$ Department of Microbiology, Faculty of Science, Bayero University, PMB 3011, Kano, Nigeria. \\ (*Correspondence author: aishabelmoh@gmail.com)
}

\begin{abstract}
Listeria monocytogenes and other Listeria species were isolated from some ready-to-eat foods sold in Kano metropolis. The method of United States Food and Drug Administration, Center for Food Safety and Applied Nutrition (FDACFSAN) was adopted in the isolation of the organism. A total of 336 food samples were screened. This included 29 beef burger, 30 yoghurt, 32 locally fermented fresh milk (nono), 34 cabbage, 45 grilled meat (tsire), 48 lettuce, 55 meat-pie and 63 roasted meat (balangu) samples. Samples were collected from December 2012 to March 2013. From these samples $38(11.3 \%)$ yielded Listeria species. Six isolates $(1.8 \%)$ were found to be $L$. monocytogenes, $31(9.2 \%)$ were found to be L. ivanovii and 1(0.3\%) was L. seeligeri. Out of the 38 isolates, $7(18 \%)$ were from 'balangu', 9 (24\%) cabbage, 14 (37\%) lettuce, 5 (13\%) meat pie and $3(8 \%)$ 'tsire' samples. L. monocytogenes was isolated from 3 lettuce samples (50\%), 2 'balangu' samples (33\%) and 1 meat-pie sample (17\%). On the other hand, L. monocytogenes was not isolated from 'tsire', beef burger, 'nono' and yoghourt samples. This study showed the presence of the organism in Kano, which could pose a threat of outbreak or sporadic cases of listeriosis with high morbidity and mortality rates.
\end{abstract}

Keywords: Isolation, Listeria monocytogenes, Ready-to-eat foods, Kano.

\section{INTRODUCTION}

Listeria monocytogenes is a ubiquitous bacterium that is responsible for food-borne illnesses in humans. It has been recovered in several countries and from many different foods of animal origin that have been linked to both sporadic cases and outbreaks of listeriosis (Thévenot et al., 2006; Chao et al., 2006). Disease incidence in humans is generally low, but in recent years great attention has been addressed to study the virulence properties of this microorganism due to the severity of the illness and the high mortality rate (20-30\%) (Vazquez-Boland et al., 2001; Dussurget et al., 2004).

The organism is wide-spread in the environment. It is found in soil, water, sewage, decaying vegetation and can be readily isolated from humans, domestic animals, raw agricultural products, food processing environment and the home (Ryser and Marth; 1999). The mode of transmission can be by ingestion of contaminated food or transmitted vertically from mother to fetus both in utero and peripartum. Other less frequent possible modes include animal-to-person transmission, resulting for example in cutaneous lesions among veterinarians, or nosocomial transmission, as documented in an outbreak in a newborn nursery through the use of contaminated mineral oil (Schuchat et al., 1991).

Human population responses to $L$. monocytogenes exposures and listeriosis are highly variable. Disease incidence is dependent on a variety of factors, including the presence of virulence factors, dose, general health and immune status of the host (Vazquez-Boland et al., 2001; Dussurget et al., 2004). Listeriosis is a rare disease with high mortality rate causing about $43 \%$ of the food poisoning in the
United State (Center for Disease Control (CDC), 2006). It is one of the most virulent food borne pathogens with 20 to $30 \%$ of clinical infections resulting in death (Ramaswamy et al., 2007). Listeriosis is responsible for approximately 2500 illness and 500 deaths in the US annually and is the leading cause of death among food borne bacterial pathogens with fatality rates exceeding even Salmonella and Clostridium botulinum (Dharmarha, 2008). In Nigeria, cases of listeriosis and death caused by the disease were not well documented. Patients might have died before they could obtain medical help because of inaccessibility in most rural areas, poor state of some health facilities and low level of awareness of $L$. monocytogenes among health professionals or absence of the selective laboratory media for the isolation due to the high cost of procurement (Greenwood, 1999). These could lead to wrong diagnosis of listeriosis, although an outbreak of listeriosis was reported in a herd of cattle by Akpavie and Ikheloa in 1992. the research was set up to isolate Listeria monocytogenes from some processed foods, Meat, Vegetables, Dairy products and identify the isolates to specie level using biochemical analysis.

\section{MATERIALS AND METHODS}

Study Area and Sample Collection

The study area was Kano metropolis. This include; Kabuga, Zoo road, Tarauni, Nassarawa, Bompai road and Municipal. These are places with high number of ready-to-eat and fast food joints. Samples were collected from December 2012 to March 2013. The samples were Meat pies, Beef burgers, Roasted meat (Balangu) and Grilled meat (Tsire), Yoghurt, Locally fermented fresh milk (Nono) Cabbage and Lettuce. 
The sample size was 336. This included 29 beef burger, 63 balangu, 45 tsire, 30 yoghurt, 32 nono, 55 meat pie, 34 cabbage and 48 lettuce samples. The work was conducted at the Microbiology/Parasitology of Aminu Kano Teaching Hospital, Kano.

\section{MATERIALS AND METHODS}

\section{Isolation of Listeria monocytogenes}

The United States Food and Drug Administration and Center for Food Safety and Applied Nutrition method of isolation was adopted (Manual, 2004). Listeria Enrichment broth (LEB) with listeria selective enrichment supplement was used for enrichment. Listeria selective agar base (Oxford formulation) fortified with Listeria selective supplement agar plates were used as the selective media for the presumptive isolation of listeria species from the processed food samples.

\section{Sample Preparation}

To obtain a true representative of the samples, the composite samples were thoroughly mixed in the following manner; nono and yoghurt were agitated; samples from tsire and balangu were chopped using sterile surgical blades; samples from lettuce and cabbage were also chopped using sterile surgical blades. Aseptic conditions were maintained throughout the period of sample analysis to prevent contamination of samples and media.

\section{Inoculation/Enrichment}

- $\quad$ Five grams or milliliters of each sample from the composite mixture was weighed and transferred into a $100 \mathrm{ml}$ capacity Erlenmeyer flasks containing $45 \mathrm{ml}$ sterilized Listeria enrichment broth base with Listeria primary enrichment supplement. The samples were properly shaken and incubated at $30^{\circ} \mathrm{C}$ for 48 hours.

- A loop-full of the broth culture was streaked onto a dried plate of Listeria selective agar base (Oxford formulation) + Listeria Selective Supplement (Oxoid, Hampshire, UK) and incubated aerobically at $37^{\circ} \mathrm{C}$ for 24 hours. Colonies that appeared brown black with a depressed center and a surrounding black halo were taken as positive for Listeria species.

- $\quad$ Triptose Soy Agar with $0.6 \%$ yeast extract (TSAYE) was sterilized and poured into Petri plates and bijour bottles for slants. Typical colonies from each LSA plate that had blackened were streaked onto TSAYE in order to purify them. The plates were incubated at $30^{\circ} \mathrm{C}$ for 24 hours. Isolates were transferred to the sterile slants of Triptose Soy Broth with yeast extract. These were incubated at $30^{\circ} \mathrm{C}$ for 24 hours and stored at $4^{\circ} \mathrm{C}$ for further use (Hitchins, 1998).

\section{Identification of isolates}

The isolates were examined with a light microscope for their morphological characteristics, Gram reaction pattern and cellular features. The isolates were further subjected to the following biochemical tests: Catalase, Oxidase and Hemolysis on sheep blood agar in order to confirm the identity of the bacterial species.

\section{Motility}

Motility at $25^{\circ} \mathrm{C}$ was performed using hanging drop procedure: a drop of suspension (a colony suspended in normal saline and incubated at $20-25^{\circ} \mathrm{C}$ for 2 hours) was placed on a cover glass and inverted over a normal slide supported on a ring of plasticine. It was examined microscopically for motile organisms, using the 10X and 40X objectives. The preparation was brought into focus by focusing first on the edge of the cover glass. True bacterial motility was observed due to the ability of an organism to move itself in different directions in a characteristic tumbling motility.

Biochemical screening of the various isolates to specie level were carried out using a standard biochemical tests with Microbact 12L; Plates 9A and 9B (Oxoid, Hampshire, UK) (Hitchins, 2011).

\section{Quality control}

Listeria monocytogenes (ATCC 19115) was used as positive controls for checking the efficiency of both culture and media.

\section{RESULTS}

In this study, a total of 336 processed foods and vegetable samples in Kano metropolis were examined for the presence of Listeria monocytogenes. From the total number of samples collected, Listeria species were isolated in 38 samples $(11.3 \%)$. Out of 38 Listerialspecies, 7 (11\%) were from Balangu, 9 (26\%) Cabbage, 14 (29\%) Lettuce, 3 (7\%) Tsire and 5 (9\%) Meat pie samples (Table 1 ). L. monocytogenes was isolated from 6 samples $(1.8 \%), 31$ isolates $(9.2 \%)$ were found to be Listeria ivanovii and $1(0.3 \%)$ was Listeria seeligeri. L. monocytogenes was isolated from 3 lettuce samples (50\%), 2 (33\%) balangu samples and 1 meat pie sample (17\%) as shown in Table 1. On the other hand, Listeria monocytogenes has not been isolated from cabbage, tsire, beef burger, nono and yoghourt samples. Listeria ivanovii has been isolated in cabbage, balangu, lettuce, meat pie and tsire samples, whereas no Listeria specie was isolated from any of the beef burger, nono and yoghurt samples (Table 1). 
Bajopas Volume 7 Number 2 December, 2014

Table 1: Occurrence of Listeria species isolated from each food sample.

\begin{tabular}{|c|c|c|c|c|c|c|}
\hline Sample & $\begin{array}{c}\text { No. } \\
\text { screened }\end{array}$ & $\begin{array}{c}\text { No. positive for } \\
\text { Listeria spp. }\end{array}$ & $\begin{array}{c}L . \\
\text { monocytogenes }\end{array}$ & $\begin{array}{c}\text { L. } \\
\text { ivanovii }\end{array}$ & $\begin{array}{c}L . \\
\text { seeligeri }\end{array}$ & $\begin{array}{c}\text { Percentage } \\
(\%)\end{array}$ \\
\hline Balangu & 63 & 7 & 2 & 5 & 0 & 11 \\
\hline $\begin{array}{l}\text { Beef } \\
\text { burger }\end{array}$ & 29 & 0 & 0 & 0 & 0 & 0 \\
\hline Cabbage & 34 & 9 & 0 & 9 & 0 & 26 \\
\hline Lettuce & 48 & 14 & 3 & 10 & 1 & 29 \\
\hline Meat pie & 55 & 5 & 1 & 4 & 0 & 9 \\
\hline Nono & 32 & 0 & 0 & 0 & 0 & 0 \\
\hline Tsire & 45 & 3 & 0 & 3 & 0 & 7 \\
\hline Yoghurt & 30 & 0 & 0 & 0 & 0 & 0 \\
\hline Total & 336 & 38 & 6 & 31 & 1 & \\
\hline
\end{tabular}

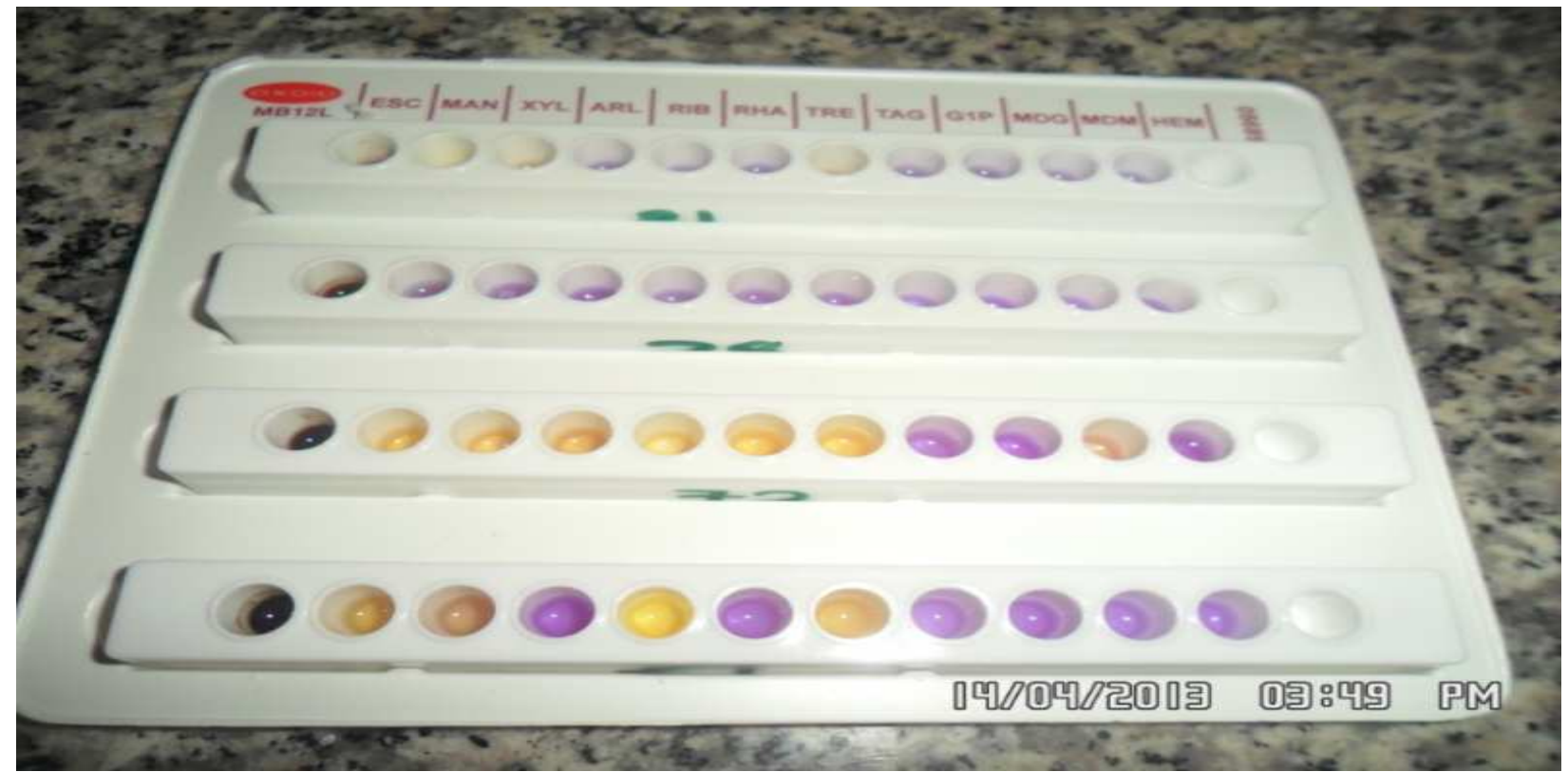

Plate 9A: Microbact ${ }^{\mathrm{TM}}$ Listeria $12 \mathrm{~L}$, self-contained biochemical based identification system for the definitive identification of Listeria species.

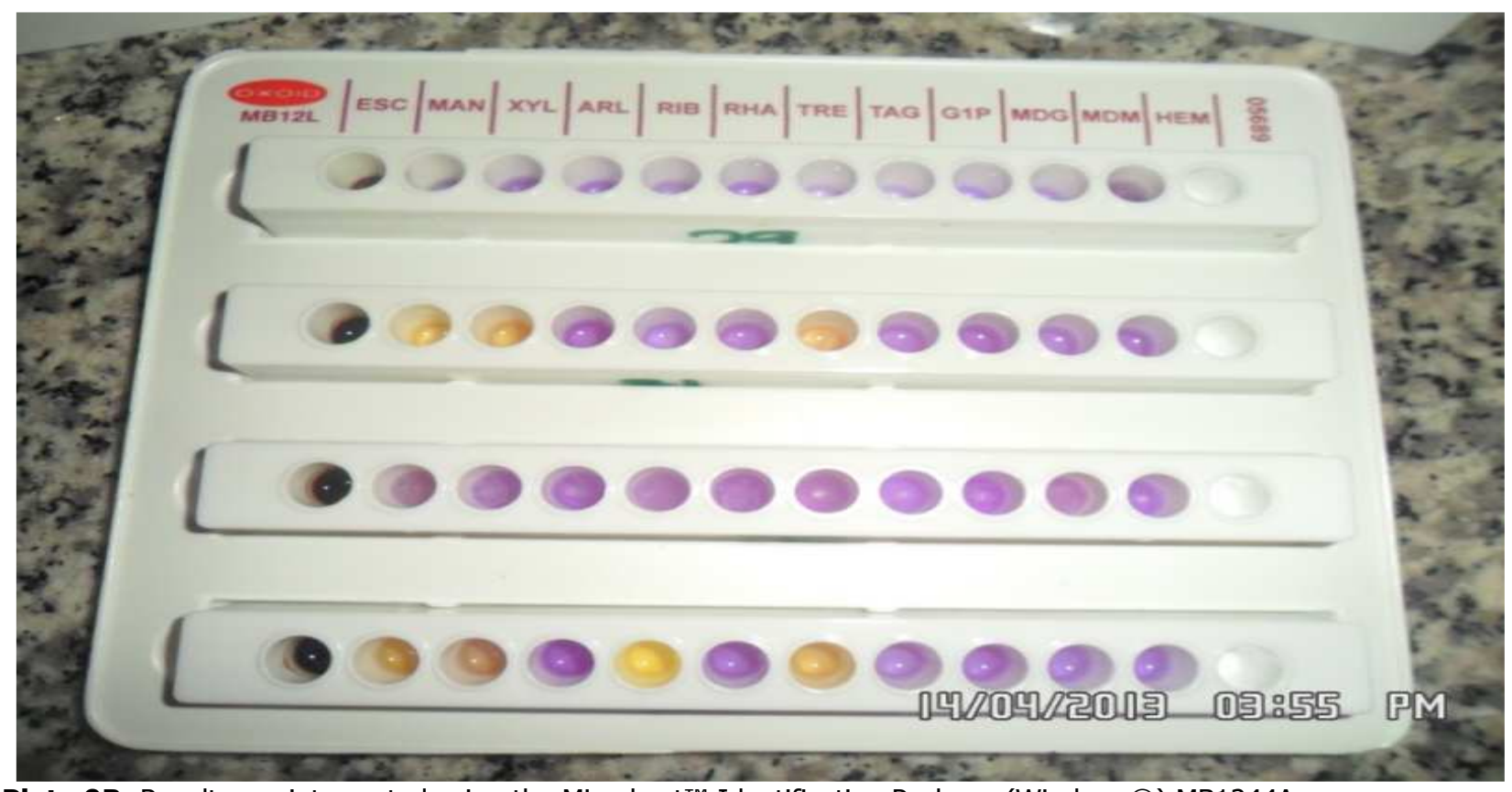

Plate 9B: Results are interpreted using the Microbact ${ }^{\mathrm{TM}}$ Identification Package (Windows $\left.®\right)$ MB1244A. 


\section{DISCUSSION}

A total of 336 samples were screened for $L$. monocytogenes and other Listeria species and these were isolated from the examined food samples. $L$. monocytogenes was isolated from lettuce, balangu and meat pie samples. L ivanovii was isolated from balangu, cabbage and lettuce samples. None of the Listeria species was isolated from beef burger, yoghurt and nono samples. The absence in both yoghurt and nono samples might be as a result of the production of bacteriocins by the starter culture used for their fermentation which suppresses the growth of L. monocytogenes. Shehu and Lamido (1994) reported an average $\mathrm{pH}$ of 3.80 for nono sampled in Zaria. Effective fermentation should occur at pH less than 4.4. Consequently, any fermentation at a pH greater than this will be deemed ineffective and will favor the survival of $L$. monocytogenes. This may probably explain why $L$. monocytogenes was not isolated.

In the present study contaminations of food product with $L$. monocytogenes were 3 lettuce samples $(6.3 \%), 2$ balangu samples (3.2\%) and 1 meat pie sample (1.8\%). The non-occurrence of $L$. monocytogenes in Burger, Tsire, Cabbage, Nono and Yoghurt is significant in public health because the products are a ready-to-eat (RTE). Most reports on the occurrence of this food borne pathogen in meats have tended to concentrate on raw meat, meat mixed with salads and poultry (Morobe et al., 2009).

Of public health concern is the occurrence of the microorganism in balangu, meat pie and lettuce. The contamination of lettuce is in agreement with the study of Little et al., (2007), which suggest occurrence of $L$. monocytogenes in prepackaged mixed salads could result from the original contamination of raw material or cross contamination during processing.

Among the food samples examined, the highest $L$. monocytogenes occurrence was encountered in the lettuce samples. Contamination of vegetables with Listeria species is thought to occur on the farm mainly

\section{REFERENCES}

Akpavie, S.O. and Ikheloa, J.O (1992) An Outbreak of Listeriosis in cattle in Nigeria. Revenue Eleveur Medicale Le veterinaire pays tropicale. 45:263-267.

Center for Disease Control (2006). Surveillance for Food-borne-Disease Outbreaks United States, 1998-2002 MMWR 55(SS10); 1-34 http://www.cdc.gov/MMWR/preview/mmwrht $\mathrm{ml} / \mathrm{ss} 5510 \mathrm{a} 1 . \mathrm{htm}$

Chao G., Deng Y., Zhou X., Xu Q., Qian X., Zouh L. and Zhu B. (2006). Prevalence of Listeria monocytogenes in delicatessen food products in China. Food control 17:971-974.

Cheesbrough M. (2006). District Laboratory Practice in Tropical Countries. Cambridge University Press, P. 434.

Dharmarha, V. (2008). "A Focus on Listeria Monocytogenes." National Agricultural Library, Food Safety Research Information Office. Retrieved 28 Feb, 2012.

Dussurget O., Pizzaro - Cerda J. and Cossart P. (2004). Molecular determinant of Listeria through soil and animal manure, although, contaminated wash water may also play a role (Ikeh et al., 2010).

The higher occurrence of the organism in lettuce could perhaps be attributed to the fact that lettuce is close to ground, and is usually in contact with farmland, soil, manure etc (Nwachuku et al., 2010). The nonoccurrence in cabbage could be due to the interlocked nature of its leaves and the opened lower leaves that are directly in contact with the soil are normally cut off during harvesting. Generally, the presence of the pathogen in lettuce raises enough concern due to the fact that it is consumed raw and by the entire populace, including listeriosis susceptible people. Therefore, creating public awareness by disseminating the information is necessary. Serious precautions regarding the food type, storage system and proper cooking should be considered while handling of food, in order to control Listerial food contamination.

This study indicated how these organisms are widely distributed in the society and may infect many people, different foods and also the environment.

\section{Conclusion}

L. monocytogenes has been isolated in Kano which pose a threat to human life and can cause outbreak of listeriosis. Many people who have been suffering from unknown causes of meningitis, abortion, still birth, septicemia, endocardities, and so on, might be infected by L.monocytogenes. The study represents a database for the isolation of Listeria species which can be used especially for further studies.

\section{Recommendations}

$>$ More research should be conducted to ascertain the presence of the organism in other food items.

$>$ Great attention has to be given to the decontamination of vegetables that are consumed raw.

monocytogenes virulence. Annual Review in microbiology 58:587 - 610 .

Greenwood, B. (1999) meningococcal meningitis in Africa. Transactions of the Royal Society of tropical medicine and Hygiene 93: 341 - 353.

Hitchins A.D. (1998). Listeria monocytogenes. In: Bacteriological Analytical Manual, US Food and DrugAdministration, AOAC INTERNATIONAL, Gaithersburg, MD, USA, 10.01-10.11.

Hitchins A.D. (2011) Listeria monocoytogenes. Chapter 10 in Jackson G.J. (Coordinator) Bacteriological Analytical Manual $8^{\text {th }}$ edition, Revision A. USA: AOAC International Gaithersburg.

Ikeh, M. A. C., Obi, S. K. C., Ezeasor, D. N., Ezeonu, I. M., and Moneke, A. N. (2010) Incidence and pathogenicity profile of Listeria sp. isolated from food and environmental samples in Nsukka, Nigeria. African Journal of Biotechnology Vol. 9(30), pp. 4776-4782. 
Little C.L, Taylor FC, Sagoo SK, Gillespie LA, Grant K. and McLauchlin J (2007). Prevalence and level of Listeria monocytogenes and other Listeria species in retail pre-packaged mixed vegetable salads in theUK. Food Microbiol. 24: 711-717.

Manual of Diagnostic Tests and Vaccines for Terrestrial Animals (2004). Listeria monocytogenes. CHAPTER 2.10.14. scientific.dept@oie.int

Morobe, I.C., C.L. Obi, M.A. Nyila, M.I. Matsheka and B.A. Gashe (2009). Molecular Characterization and Serotyping of Listeria monocytogenes with a Focus on Food Safety and Disease Prevention, BiochemicalTesting, Dr. Jose C. Jimenez-Lopez (Ed.), ISBN: 978953-51-0249-6, InTech, Available from:http://www.intechopen.com/books/bioc hemical-testing/molecular-characterizationand-serotyping-of-Listeriamonocytogenes-

Nwachukwu, N.C., Orji, F.A, Iheukwumere, I. and Ekeleme, U.G . (2010). Antibiotic Resistant Environmental Isolates of monocytogenes from Anthropogenic Lakes in Lokpa-Ukwu, Abia state of Nigeria. Australian Journal of Basic and Applied Sciences 4(7) 1571-1576.

Ramaswamy V., Cresence V.M., Rejitha J.S., Leshmi M.U., Dharsana K.S., Prasad S.P. and Vijila
H.M. (2007). Listeria-review of epidemiology and pathogenesis.(PDF). J. Microbiol Immunol Infect. 40 (1): 4 - 13.

Ryser. E.T. and E. H. Marth (ed). 1999. Listeria, Listeriosis and food safety. $2^{\text {nd }}$ ed. Marcel Dekker Inc. New York. NY.

Schuchat A, Lizano C, Broome CV, Swaminathan B, Kim C. and Winn K. (1991) Outbreak of neonatal listeriosis associated with mineral oil. Pediatric Infectious Diseases Journal 1991;10:183-9.

Shehu, L.M. and Lamido, T. (1994). Isolation and characterization of $E$. coli Strains from locally fermented milk (nono) in Zaria,Nigeria. West African Journal of Biological Science 1: 17-24.

Thevenot D., Dernburg A. and Vernozy-Rozand C. (2006). An updated review of listeria monocytogenes in pork meat industry and its products. Journal of Applied Microbiology 101: 7-17.

Vazquez - Boland J.A., Kuhn M., Bercehe P., Charkraborthy T., Dominguez Bernal G., Goebal W., Gonzalez - Zorn B., Wehland J., Kreft J. (2001): Listeria pathogenesis and molecular virulence determinants. Clinical microbiology Review 14: $584-640$. 